\title{
Article \\ Performance-Driven Engineering Design Approaches Based on Generative Design and Topology Optimization Tools: A Comparative Study
}

\author{
Loris Barbieri *(D) and Maurizio Muzzupappa (D)
}

check for updates

Citation: Barbieri, L.; Muzzupappa, M. Performance-Driven Engineering Design Approaches Based on Generative Design and Topology Optimization Tools: A Comparative Study. Appl. Sci. 2022, 12, 2106. https://doi.org/10.3390/ app12042106

Academic Editors: Marco Mandolini and Paolo Cicconi

Received: 19 January 2022 Accepted: 15 February 2022 Published: 17 February 2022

Publisher's Note: MDPI stays neutral with regard to jurisdictional claims in published maps and institutional affiliations.

Copyright: (C) 2022 by the authors. Licensee MDPI, Basel, Switzerland. This article is an open access article distributed under the terms and conditions of the Creative Commons Attribution (CC BY) license (https:// creativecommons.org/licenses/by/ $4.0 /)$.
Department of Mechanical, Energy and Management Engineering (DIMEG), University of Calabria, P. Bucci 46C, 87036 Rende, CS, Italy; muzzupappa@unical.it

* Correspondence: loris.barbieri@unical.it

\begin{abstract}
The advent of Additive Manufacturing (AM) is uncovering the limits of the current CAD systems and, at the same time, is highlighting the potentials of the Topology Optimization (TO) and Generative Design (GD) tools that had not been fully exploited until now. Differently from the traditional design approach in which designers occupy a predominant role in each stage of the design process, the introduction of such tools in the product development process pushes toward simulationdriven design approaches which imply a significant change in the role of the designer. To this end, the paper presents a comparison of two different design methods for Additive Manufacturing based on the adoption of TO and GD tools. The comparison aims to offer a reflection on the evolution of the traditional approach when TO and GD tools are used, and to highlight the potential and limitations of these optimization tools when adopted in an integrated manner with the CAD systems. Furthermore, this comparative study can be a useful and practical source for designers to identify the most appropriate approach to adopt based on their needs and project resources. The comparative study is carried out through the design study of a prototype of a rocker arm and a brake pedal for the Formula Student race car. Their results, compared in terms of mechanical performances, show that both TO and especially GD tools can be efficiently adopted early in a design process oriented to AM to redesign components to make them lighter and stronger.
\end{abstract}

Keywords: Additive Manufacturing; topology optimization; generative design; CAD systems; design methods

\section{Introduction}

Additive Manufacturing (AM) has brought radical innovations in the technological field for the production of products and, at the same time, represents a revolution in the industrial design and product development fields because it leads engineers to radically rethink the design approach, and in particular, the modeling activities carried out with Computer Aided Design (CAD) systems. In fact, the CAD systems have been developed and constantly improved with a view to ensure the manufacturability of the products by means of conventional subtractive techniques, which entail the progressive removal of material from an initial volume to obtain the desired final shape.

The advent of Additive Manufacturing is uncovering the limits of the current CAD systems and, at the same time, is highlighting the potentials of the Topology Optimization (TO) and Generative Design (GD) tools that had not been fully exploited until now. AM is indeed the enabling technology that can bring the outcome of these optimization tools to life, allowing as it does for the fabrication of very complex geometries. In fact, compared to a conventional design approach, an integrated use of optimization tools and AM technologies allows the production of lighter but stronger parts with complex organic shapes instead of solid fills [1,2]. Furthermore, the designer is granted the freedom to model or redesign a 
product optimized for a specific application without regard for the restrictions of assembly, part standardization, or traditionally restricted geometries [3].

Although it is a relatively recent technology, created in the 80s and emerged in the 90s, AM was reserved only for prototype fabrication in the beginning, instead now it is used to manufacture operable parts in many industrial fields such as aerospace, automotive, medical, and consumer products [4-9]. It is therefore evident how necessary and urgent expanding the capabilities and functionalities of current CAD systems is by facilitating and encouraging an even easier and more efficient integration with TO and GD tools. Furthermore, AM technologies are giving greater importance to and promoting these tools to support the concept and modeling design stages too rather than for validation and optimization only.

On the basis of these considerations, the paper presents a comparison of two different design methods for Additive Manufacturing based on the adoption of Generative Design and Topology Optimization tools. The comparison is carried out through the design study of a prototype of a rocker arm and a brake pedal for the Formula Student race car that allows to highlight the potentials and limits of these optimization tools when adopted in an integrated manner with the CAD system. The paper also provides a practical and useful input for reflection on the use of TO and GD tools to support designers' work and how they influence the design process.

\section{Design Methods Based on TO and GD Tools}

According to a conventional engineering design approach, the process starts in the conceptual stage by developing the functional specifications, over the user needs, that are adopted in the subsequent modeling stage to be translated into geometric shapes by means of a CAD system. In particular, the CAD system is used to perform a detailed $3 \mathrm{D}$ representation of the final object and create accurate technical drawings. The threedimensional models are then validated with simulation tools, i.e., CAE (Computer Aided Engineering) and CAM (Computer Aided Manufacturing) tools, by means of analysis and testing activities, before being transferred into manufacturing equipment, such as machining centers, lathes, or mill machines, to make the product. By using such an approach, if on the one hand, the CAx (Computer Aided Technologies) systems [10] support and simplify designers' jobs, on the other hand, they can influence the design process and limit their creativity [11]. This is mainly because the current CAD systems allow designers to create 3D models according to a feature-based parametric modeling approach that was introduced at the end of the 1980s. The main advantage introduced by this technique was its capability to produce very flexible designs defined by its design variables and parametric features. In the following years, the CAD systems were enriched with further modeling functions and specific features, and were integrated with CAE and CAM modules to allow engineers to operate within a single environment. In particular, CAE modules allow to perform finite element analysis (FEA) in which structural problems are solved by defining the geometry, boundary conditions, and initial conditions [12], while CAM are used to assess manufacturability of the geometry created in the CAD part. When tools and tool paths are found satisfactory $\mathrm{CNC}$ (computer numerical control)-code can be generated and used in a real machine to manufacture the geometry, if a CNC-coder for the machine has been implemented in the CAD/CAM software [13]. Nevertheless, the modeling approach has remained essentially unchanged and fails in supporting designers to build complex geometry and high functional performance models [1].

The advent of AM has broken down the technological constraints of subtractive manufacturing and therefore it has offered designers enormous potential for the realization of geometries that were impossible to achieve until a few years ago. Despite growing awareness of these potentials, as abovementioned, current CAD systems do not put engineers and designers in a position to fully exploit them. This is because designers and design engineers must adapt the functionalities conceived for conventional manufacturing methods to generate very complex geometries. In fact, CAD systems use the same terminology 
for these features as those used in manufacturing and design. These features refer then to specific conventional manufacturing processes developed to form them efficiently. It is therefore clear that the use of the actual CAD functionalities for a design oriented to AM is a tedious and labor-intensive activity, the result of which depends a lot on the individual skills and experience of the modelers [14]. In this context, it results evident that TO and GD tools could be an efficient and useful aid not only for the analysis and optimization of the geometry but especially to support engineers, in the conceptual and modeling stages, for defining the geometry of the 3D models.

Unlike the traditional design approach, in which CAD systems are adopted to generate a detailed geometry that follows the designer's indications, the introduction of TO and GD tools allows designers to focus primarily on the function, instead of the form, delegating optimization tools to generate design alternatives. In fact, as depicted in Figure 1, the first stage, common to both approaches, provides the adoption of the CAD system but for the definition of the functional surfaces only. Additionally, the last stage is common to both approaches and consists of the use of CAM systems to ensure correct manufacturability. Differently from the abovementioned CAM systems, these systems, specific for AM, are adopted to maximize printing capabilities, optimize the orientation of the part and the number and type of supports and, just recently, to predict deformations of the part due to the high-stress gradient generated during printing [15]. In those cases where the thermal analysis identifies geometric distortions, geometric compensation can be applied to the design to print pre-deformed parts to obtain the nominal geometric tolerance after support removal $[16,17]$. In both approaches, either by adopting TO or GD tools, after the product has been made using AM techniques, the manufacturing process ends by performing the conventional post-processing of thermal treatments, detachment of the printed part from the plate by removing the supports, surface finishing through laser polishing, and CNC machining operations may be required too to refine or meet geometric dimensioning and tolerancing requirements of the functional surfaces.

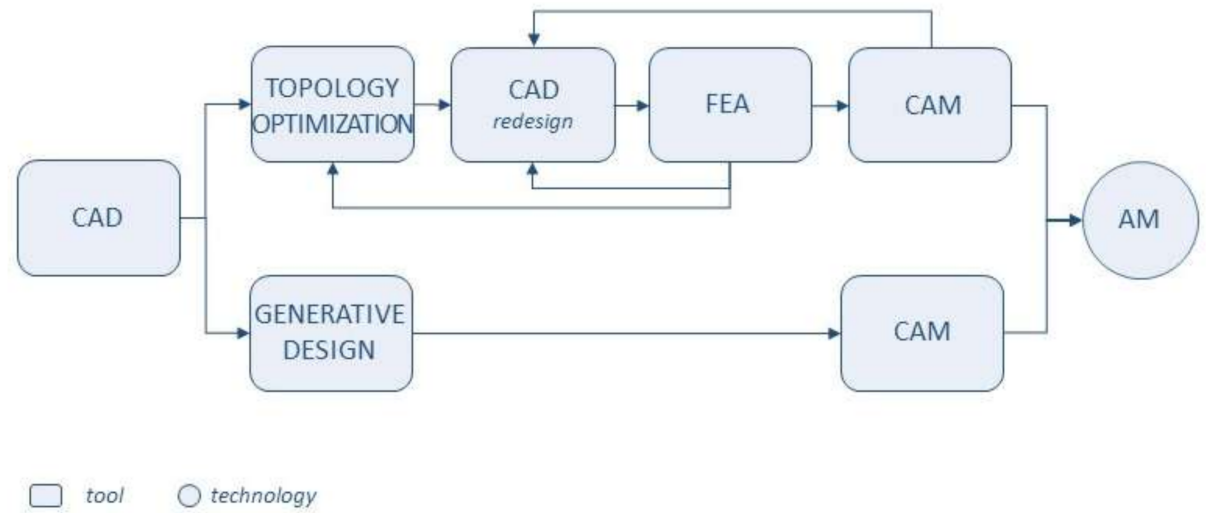

Figure 1. Engineering design methods with the introduction of TO and GD tools.

\subsection{Topology Optimization}

TO is a computational design methodology [18-20] that by means of using finite element analysis allows to generate an optimal material layout in a given design domain subject by respecting given constraints, loading, and boundary conditions. In particular, the design domain is discretized into finite elements, and one of a number of optimization techniques is used to determine the distribution of the material. This is usually achieved by minimizing the mass while preventing yielding or maximizing the stiffness constraining the mass to a target value. TO experienced rapid growth at the beginning of the 1990s as it became easily distinguishable from Shape or Size Optimization concepts [21,22]. In the following years, TO tools evolved rapidly from the academic to the industrial field, in fact, they are used effectively in various application areas [23-34] and, in the everyday industrial practice, it is frequently used for the redesign of already existing products [35-39]. Recently, thanks to the evolution of CAD systems and the appeal of additive technologies, different 
software houses have started to integrate TO modules within the modelling environment. This need arises from the limit of this optimization process which, as depicted in Figure 1, requires a redesign phase to achieve a manufacturable design or to merely make small changes to the geometry. This redesign phase results not only in an increase in the final mass of the piece, but also in an increase in the design processing time. This issue is due to the fact that $\mathrm{TO}$ requires a finite element model, and its results are represented using a tessellation model that cannot be converted directly into a parametric CAD part and, furthermore, it cannot be manipulated directly within the CAD systems especially when the mesh is very dense. Despite the various attempts and efforts made in this direction, all of them lack an efficient integration between TO tools and CAD systems [40]. For this reason, in the last decade, various manual and semi-automatic methods were proposed in order to support designers to interpret and convert topology optimization results into a parametric CAD model [41-47]. Recently, some CAD systems have provided functionalities to operate directly on the results of topological optimization analysis. These are mainly sculpting and free-form modeling tools to which mechanical engineers are less accustomed to than a traditional feature-based modeling approach. As a consequence, in daily industrial practice, engineers and designers perform a remodeling of TO results necessary to achieve a manufacturable feature-based geometry. Most of the time the procedure is operated manually, and the part is modeled in a CAD environment using the mesh as a guideline during the modeling [48]. As depicted in Figure 1, the design process starts with a simple geometry that defines the design space and functional surfaces. Then, the 3D model is imported into the TO environment in which, in addition to loads and constraints, the objective functions that are usually expressed in terms of minimization or maximization for the given design parameters must also be defined. After that phase, the simulation can be launched and the solver generates the optimized geometry. The topological optimization solver is an optimization algorithm. In this context, there are several kinds of algorithms currently used that can be classified in deterministic and stochastic algorithms [22,23]. The most commonly available commercial software performs a TO analysis by using the gradient-based density approach that is characterized by a design variable, ranging from 0 (void elements) to 1 (solid material), assigned to discretized elements representing an artificial density of material $[49,50]$. The solution is found through an iterative process [51] called nested formulation [52]. In the next step, it is a designer's job to re-design the model by removing material where possible, according to the topology analysis' results. Then, during the redesign stage, the designer creates a feature-based geometry that fits the theoretically optimal one, provided by the TO tool, but at the same time, it also satisfies technological constraints. The CAD model is then adopted by a simulation expert to perform an FEA and CAM validation, through an iterative process, before proceeding with its realization by means of Additive Manufacturing technologies.

\subsection{Generative Design}

GD tools use artificial-intelligence-based algorithms [53-55] to generate an array of design options that meet predetermined criteria, based upon initial user preferences, such as materials, design space and functional surfaces, performance requirements, and manufacturing constraints [56]. In particular, they can generate a number of different design solutions, that the designer would never have thought of, and with better performances compared to a component designed with traditional methods in terms of mass reduction, strength improvement, and reduction in the number of assembly parts.

Research on Generative Design started in the early 70s when the first design algorithms that mimicked nature were born [57]. Then, with the advent of parametric CAD tools, GD design was studied with a more practical approach, but only in the first decade of the century, when the first attempts of using GD in academic research for applications in the architectural fields were made [58-60]. Recently, thanks to the significant increase in computing power available, generative methods have begun to be adopted to the design of products [61-63]. This is due to the fact that, in recent years, generative software has 
been put into the market as plug-in modules for CAD systems that support designers to create and generate more efficient designs that are lighter, stronger, and in some cases, more artistic. In fact, nowadays, more and more industrial manufacturing companies are starting to experiment with the adoption of such tools to redesign products or generate new concepts that are reworked by designers $[22,64]$. To this end, a prime example is Philippe Starck's A.I. chair for Kartell, revealed during the Salone del Mobile in Milan in 2019, in which the GD technology was adopted to serve as a co-creator by providing design alternatives generated according to parameters such as materials, production methods, and cost constraints, supplied by the designer.

As depicted in Figure 1, the design process starts by using a CAD system in order to create a starting shape and obstacle geometry. Then, the user provides the functional specification including the material, functional surfaces related to mechanical interferences, loads and constraints, and the desired manufacturing processes, such as molding, machining, and Additive Manufacturing. The user also defines the desired target, such as a weight reduction or maximizing stiffness. From there, the tool cycles through the prescribed design space to generate a plethora of optimized and validated concept shapes. This can be completed using genetic algorithms and neural networks. These algorithms are based on machine learning techniques for training artificial intelligence, due to which the neural network simultaneously serves as an assistant both in the construction of a mathematical model of the optimized product and in the process of its interpretation, taking into account, for example, manufacturing parameters. An advantage in this phase is that simulations are made on a cloud-based system so, despite the performances of the designer's computer, demanding GD studies can be undertaken. After that, the results obtained are shown to the designer. Here, the GD tool supports designers in identifying the best concept for their study by allowing them to perform comparison and trade-off studies on the basis of the desired key performance indicators. The designer can then select the most appropriate solution and validate the geometry through a CAM tool before proceeding with the manufacturing. The result of the optimization process can be directly prototyped by means of AM technologies. Nevertheless, the geometry can be modified by means of built-in modeling tools that allow to manipulate control points or define cross-section profiles and edit the geometry to generate more relevant solutions $[65,66]$.

\section{Case Studies}

The case studies concern two mechanical components of a Formula Student race car built by the racing division of the University of Calabria. In particular, the rocker and the brake pedal were taken into consideration. These components were designed by the racing division following a traditional approach in order to be manufactured through conventional technologies. These mechanical components were taken into account to perform a redesign, by means of the adoption of TO and GD tools, in order to realize more performing components. To this end, the design was oriented to make components that are stiffer and lighter than those made using the traditional design approach. In addition to the Ergal-aluminum alloy 7075-T6 (density $2.81 \mathrm{~g} / \mathrm{cm}^{3}$; Young's modulus $71.70 \mathrm{GPa}$; Poisson's ratio 0.33; yield strength $505 \mathrm{MPa}$; tensile strength $570 \mathrm{MPa}$ ), that was adopted to manufacture the components designed through the traditional approach, the titanium Ti6 was also considered (density $4.43 \mathrm{~g} / \mathrm{cm}^{3}$; Young's modulus $113.76 \mathrm{GPa}$; Poisson's ratio 0.35; yield strength $945 \mathrm{MPa}$; tensile strength $1055 \mathrm{MPa}$ ). The software used for modeling and performing optimization and generative design analyses was Autodesk Fusion $360^{\circledR}$ [67].

\subsection{Rocker Arm}

The first case study considered was the redesign of the rocker arm, depicted in the following figure (Figure 2), mounted on the race car developed for the Formula SAE by the Unical Racing Team of the University of Calabria. In particular, Figure 2 shows the assembly of the right rear rocker, also known as bell crank or linkage, that is located low in the chassis and connected with the upper side of the wheel, where the upper suspension arms meet 
the upright. The rocker also mounts an antiroll bar. The function of this component is to translate the pull rod motion into the rotary force and the up/down motion on the suspension system.

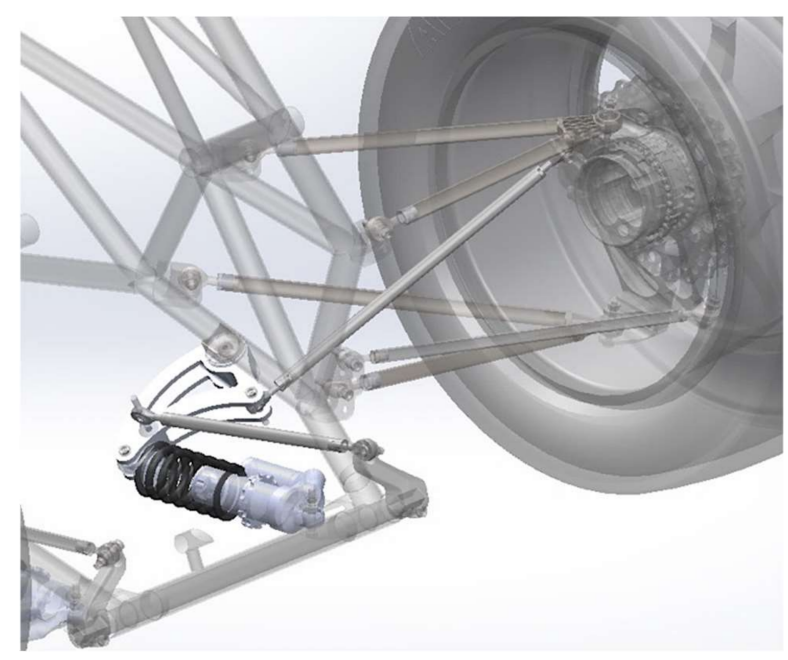

Figure 2. Assembly view of the right rear rocker.

The following figure (Figure 3) shows the geometry of the rocker designed according to a traditional method. This component was made in Ergal and worked with conventional machine tools. In particular, it was fabricated by means of a 5-axis machining center Yamazaki Mazak, VARIAXIS j-600/5X. However, this geometry could also be fabricated with a 3-axis machine.

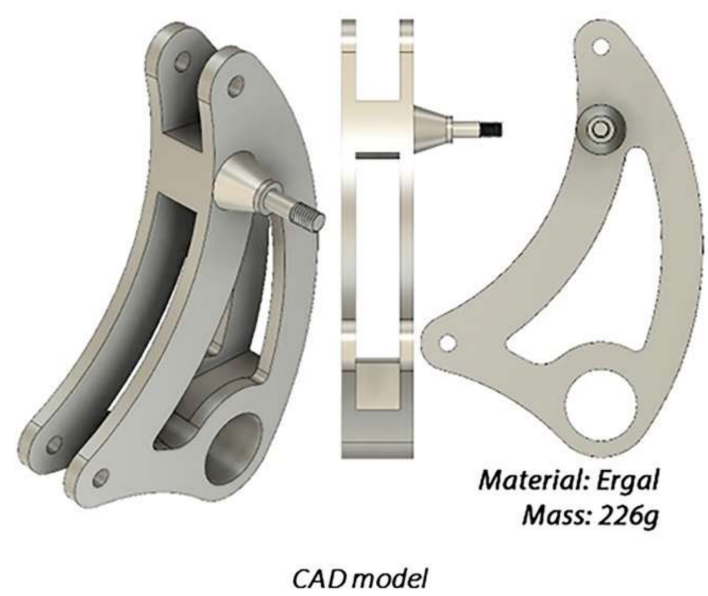

Figure 3. Rocker designed through a traditional design approach oriented to conventional manufacturing technology.

As abovementioned, the final design was achieved by means of an iterative trial and error approach based on the adoption of CAD systems for the modeling and FEM tools to assess and verify the geometry. In particular, as depicted in Figure 4a, the boundary conditions, adopted both for the FEM simulation and the optimization studies, were defined taking into consideration the two most critical cases: acceleration in corners and acceleration in straight lines. In the first case, there is a distribution of the maximum load $(2000 \mathrm{~N})$ between the shock absorber $(1300 \mathrm{~N})$ and the antiroll bar's tie rod $(700 \mathrm{~N})$. In the second case, the antiroll bar is not subjected to stresses, therefore, the $2000 \mathrm{~N}$ load is discharged only on the spring-shock absorber group. 

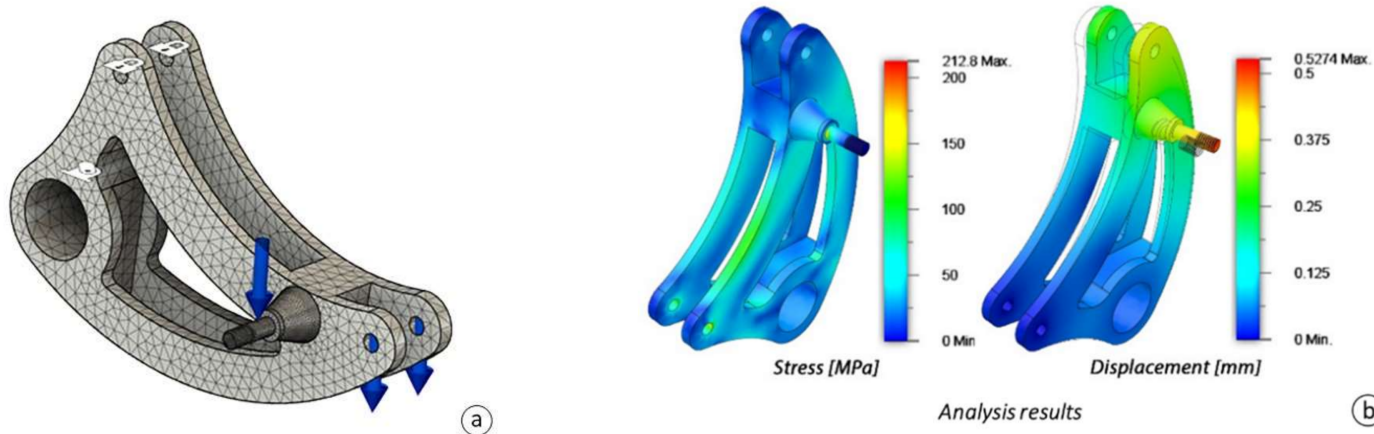

(b)

Figure 4. Rocker designed through a traditional design approach: loading conditions (a) and results of FEM analysis (b).

As depicted in Figure $4 \mathrm{~b}$, the component features a weight of $226 \mathrm{~g}$, the maximum displacement of $0.52 \mathrm{~mm}$, and a minimum factor of safety (FoS), based on the yield strength stress values, of 2.4. As abovementioned, the redesign of this component, by means of the adoption of TO and GD tools, was carried out with the aim to improve its performance by improving its stiffness and reducing its weight.

\subsubsection{Topology Optimization Approach}

As depicted in Figure 1, the process started with the adoption of the CAD system that was adopted by the designer to model the initial design space. The functional surfaces were also identified and modelled, i.e., green volumes shown in Figure 5. The geometry was then imported within the topology optimization environment in which the material was assigned, the constraints and loading conditions were defined, and the two objective functions were to maximize stiffness and target mass $\leq 30 \%$. As depicted in the following figure (Figure 5), the result of the topological optimization analysis has a mass of $193 \mathrm{~g}$. This tessellated model was then redesigned and the final feature-based geometry, validated with FEM analysis, showed a mass of $221 \mathrm{~g}$ with a maximum displacement of $0.28 \mathrm{~mm}$ and a minimum FoS of 2.4. The results of this TO analysis do not have a particularly complex geometry and the rocker can be manufactured both through conventional and AM technologies.
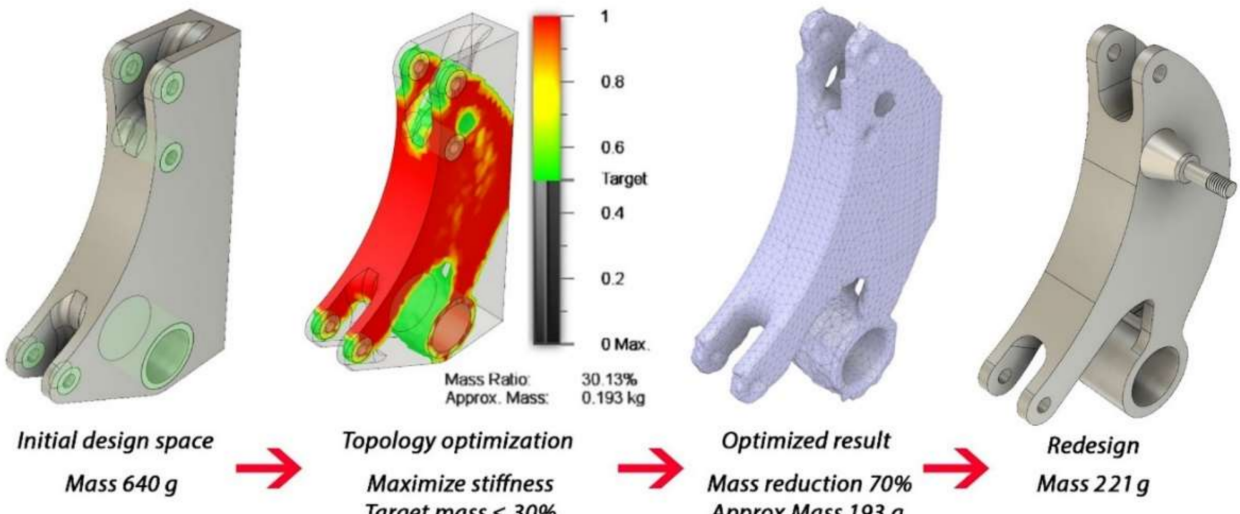

Figure 5. Stages of the TO approach for the redesign of the rocker in Ergal.

The following figure (Figure 6) shows the results of the TO approach for the redesign of the rocker in the case in which titanium is used as a material. In this case, the objective functions were to maximize stiffness and target mass $\leq 20 \%$. The initial design space was the same as that defined in the previous analysis, while the TO results showed an $80 \%$ mass reduction compared to the initial design space of $1000 \mathrm{~g}$. Nevertheless, the redesigned 
process performed to obtain a feature-based CAD model resulted in a slight increase in mass whose final value was $223 \mathrm{~g}$.

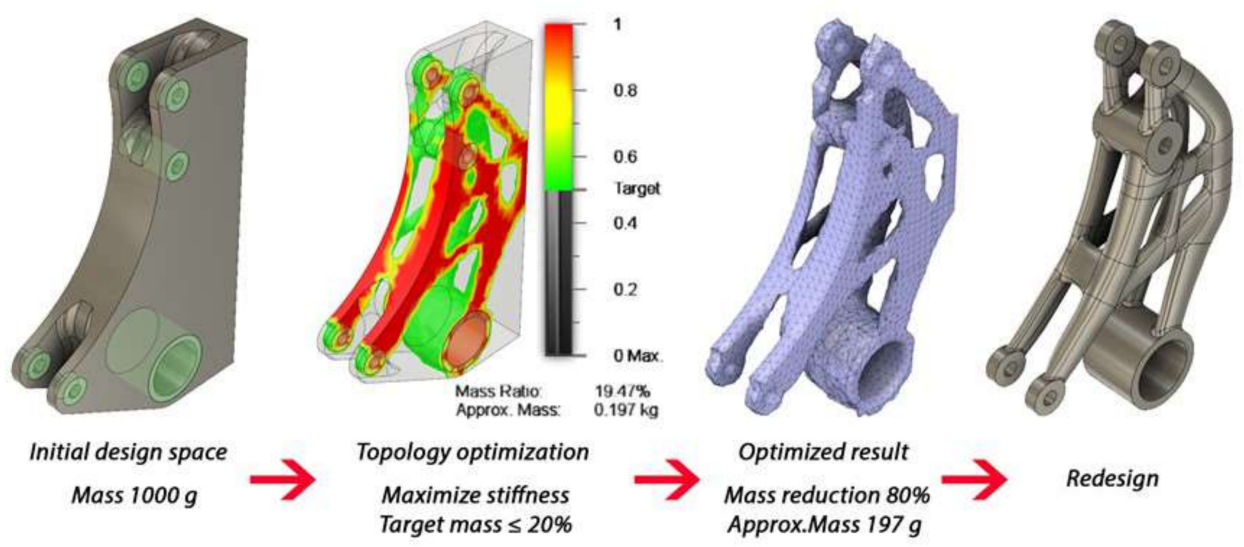

Figure 6. Stages of the TO approach for the redesign of the rocker in titanium.

As abovementioned in Section 2.1, the redesign operations entailed the need to verify and validate the final geometry by means of FEM analysis (Figure 7), the results of which show a maximum displacement of $0.33 \mathrm{~mm}$ and a minimum FoS of 3.5. In this case, the redesigned model presents very complex geometry that can be manufactured through AM technologies only. EOSINT M 280, an industrial 3D printer made by EOS GmbH of Munich (Germany), is adequate for the fabrication of this component. It is based on the DMLS (Direct Metal Laser Sintering) process that uses a $\mathrm{CO}_{2}$ laser with high power for sintering the metallic powder material according to the CAD file [68].

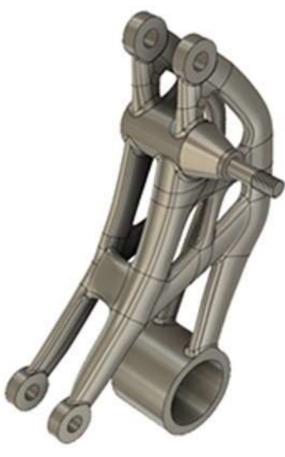

CAD model

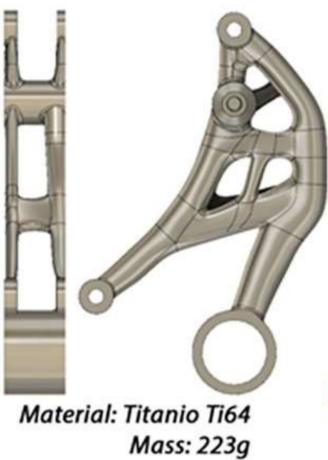

Mass: $223 g$

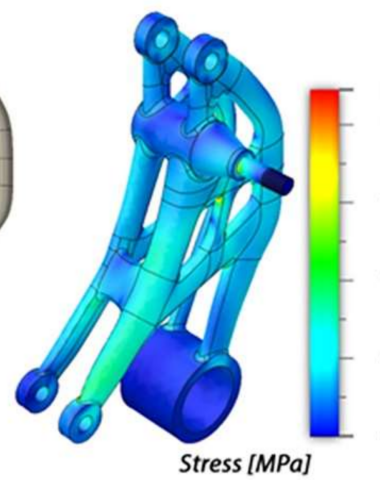

Stress [MPa]

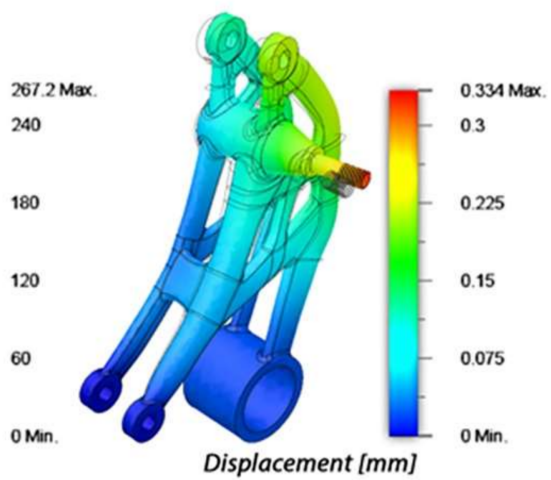

Analysis results

Figure 7. Redesigned rocker in titanium validated through FEM analysis.

\subsubsection{Generative Design Approach}

As well as for the TO approach, also in the case of GD the design process started by using a CAD system in order to define functional surfaces and obstacle geometry (Figure 1). Unlike the TO, a starting shape was not adopted. Subsequently, the same constraints and loading conditions adopted for the TO analysis were defined. While, the objective functions were to maximize stiffness, safety factor of 2, and target mass of $150 \mathrm{~g}$. Additionally, in this case, the Ergal and titanium materials were taken into account. This generative design study produced 10 design solutions. In order to perform a direct comparison, with the same material and minimum FoS, with the resulting designs of the different approaches, the solution of the generative design process was considered that presented a minimum FoS of 2.4 which has a mass of $140 \mathrm{~g}$ and a maximum displacement of $0.30 \mathrm{~mm}$. Furthermore, since the field of application is that of racing cars, the solutions showing the best results in terms of performance were also considered. As a consequence, the following figures depict, 
respectively, the best outcomes related to the adoption of the Ergal (Figure 8), with a mass of $146 \mathrm{~g}$, a maximum displacement of $0.36 \mathrm{~mm}$, and a minimum FoS of 3; and titanium (Figure 9) materials, with a mass of $149 \mathrm{~g}$, a maximum displacement of $0.50 \mathrm{~mm}$, and a minimum FoS of 2. Furthermore, the aluminum rocker can be manufactured by means of conventional and AM technologies while the titanium component requires the adoption of AM technologies.

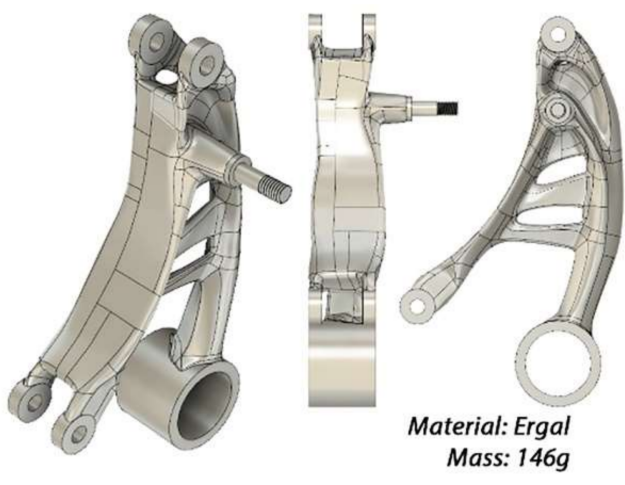

CAD model

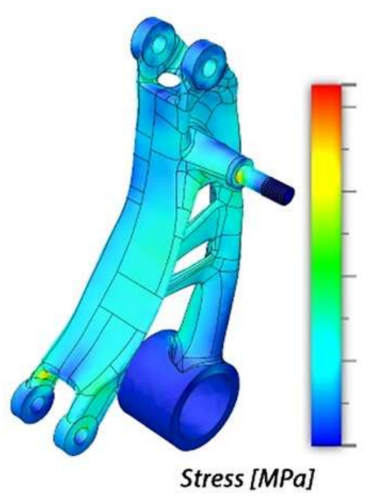

Stress [MPa]

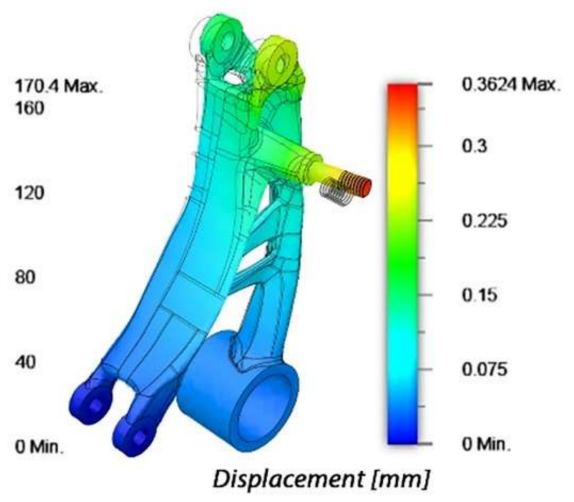

Analysis results

Figure 8. Aluminum rocker designed by adopting GD tools.
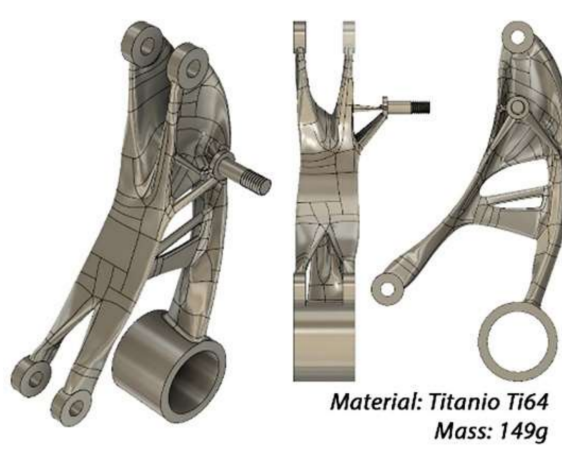

CAD model

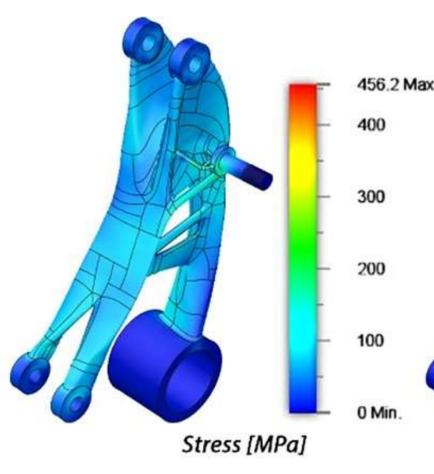

Analysis results

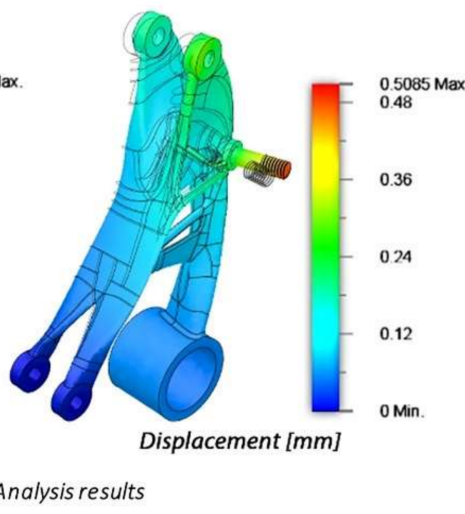

Figure 9. Titanium rocker designed by adopting GD tools.

\subsection{Brake Pedal}

A second case study examined is the brake pedal. This mechanical component acts as a lever, supplying energy from the pressure of the user's foot to a hydraulic device that actuates the brake calipers. The geometry of the pedal, depicted in Figure 10, was designed according to a traditional approach in order to be manufactured through traditional machine tools, and specifically a 3 -axis milling machine.

\subsubsection{Topology Optimization Approach}

As depicted in Figure 11, the topological optimization of the brake pedal was carried out by preserving its outer shape and filling the void areas. Using Ergal as a material, the weight of the design space is $227 \mathrm{~g}$. To improve its performance, and thus its stiffness, the objective function set in the topological study was target mass $\leq 70 \%$. 


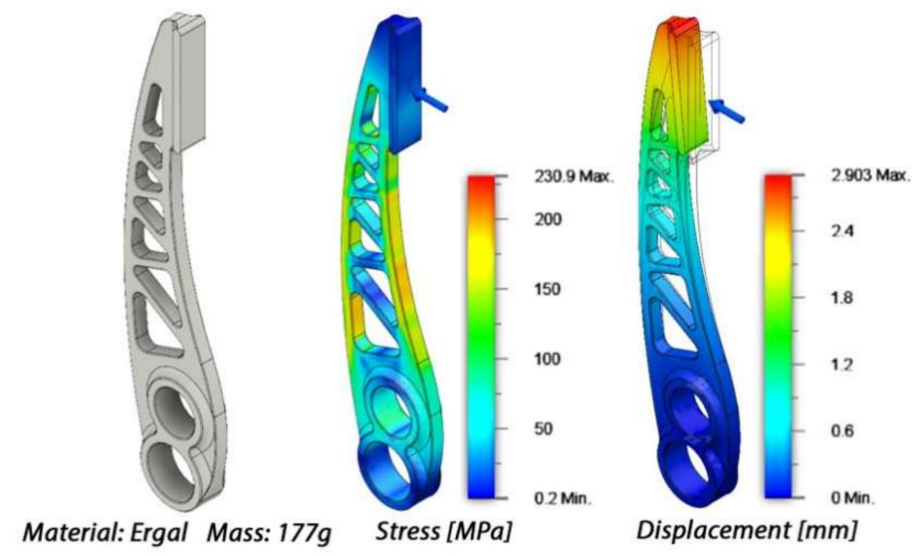

Figure 10. Brake pedal designed through a traditional design approach oriented to conventional manufacturing technology.

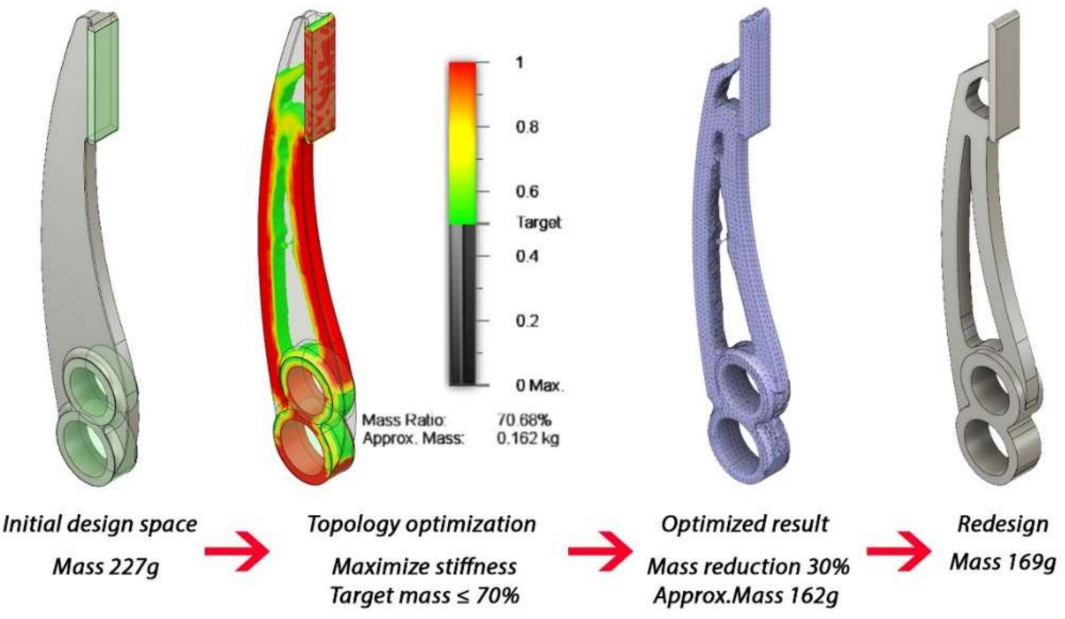

Figure 11. Stages of the TO approach for the redesign of the brake pedal in Ergal.

The redesigned component had a final weight of $169 \mathrm{~g}$. As a result of the FEM analysis, this solution shows lower performance than the one designed through the traditional approach. Since the results of the topological analysis show that the most stressed area is along the edges of the pedal, a second topological analysis was performed in which the initial design space was edited by enlarging the back area.

As depicted in Figure 12, in this second topology optimization analysis, the initial mass increased to $280 \mathrm{~g}$. To achieve, in terms of weight, a result comparable to the brake pedal designed through the traditional approach (Figure 10), the objective function was objective mass $\leq 58 \%$. The following figure (Figure 13) shows the final geometry as a result of the redesign operations.

As performed for the rocker, a topology optimization of the pedal in titanium was carried out. In particular, since the initial design space of the pedal in titanium reached $442 \mathrm{~g}$, the target set to have a similar weight to the initial component (Figure 10) was 37\%. This analysis did not provide satisfactory results, so they were not taken into consideration. 


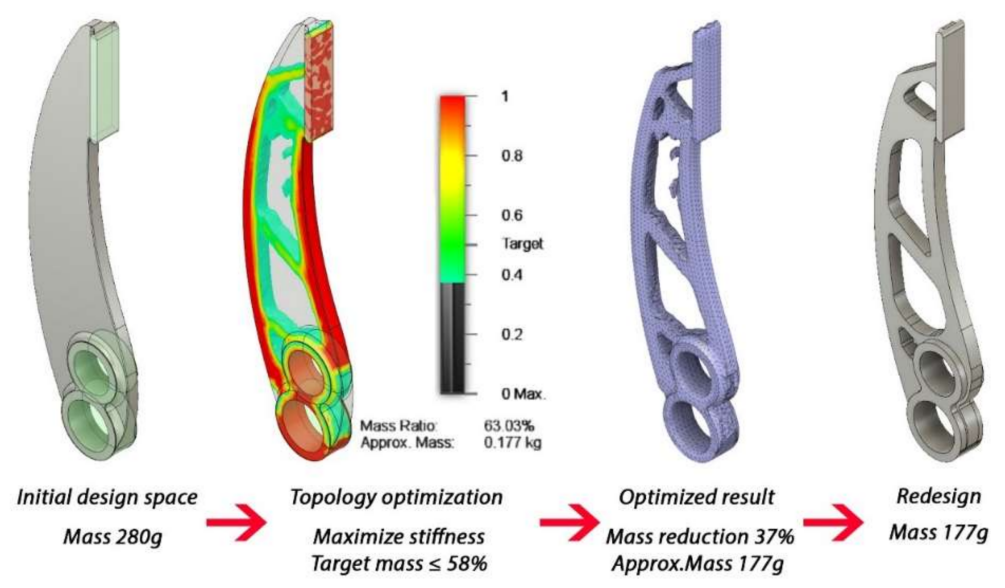

Figure 12. Stages of the second TO of the Ergal brake pedal.
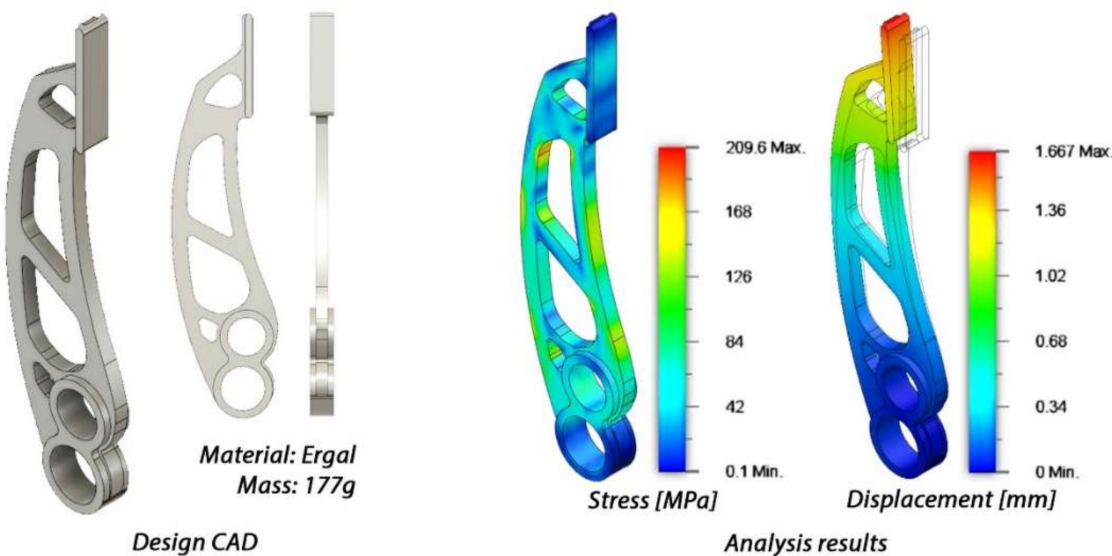

Figure 13. Redesigned brake pedal in Ergal validated through FEM analysis.

\subsubsection{Generative Design Approach}

The same constraints and loading conditions adopted for the TO analysis were defined. While the objective functions were to maximize stiffness, safety factor of 2 , and target mass of $165 \mathrm{~g}$. Ergal and titanium materials were considered. This generative design study produced 10 design solutions. The best result, in terms of performance, for the aluminum material is shown in the following figure (Figure 14).
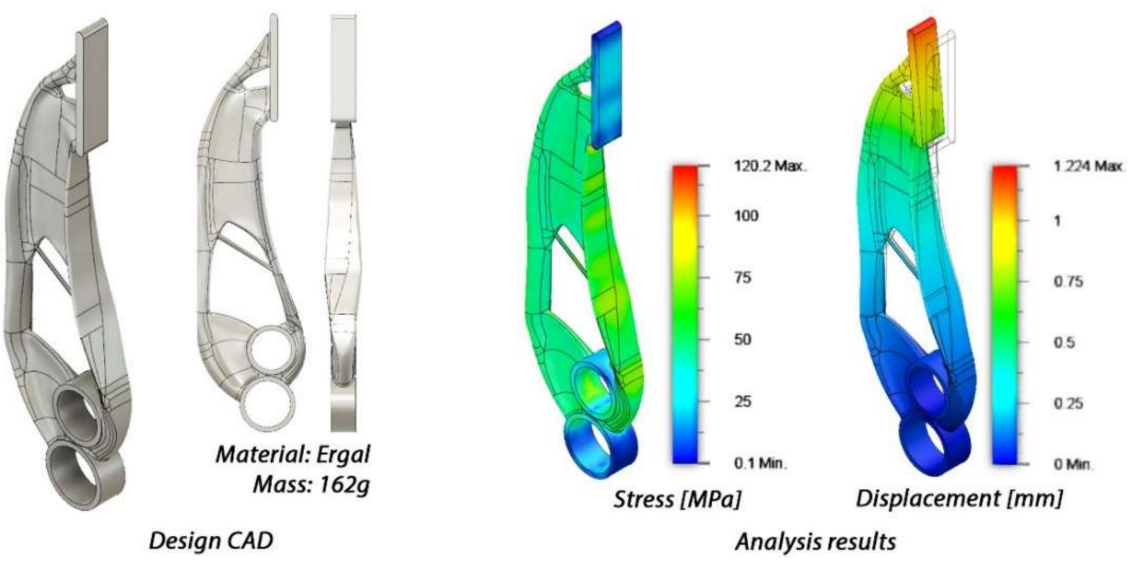

Figure 14. Redesigned brake pedal in Ergal validated through FEM analysis.

Contrary to topological optimization, which does not provide valid results with the titanium material, generative design succeeds in addressing the targets imposed in the 
analysis. As depicted in the following figure (Figure 15), although the geometry is slimmer than the Ergal pedal (Figure 14), their weights are equal.
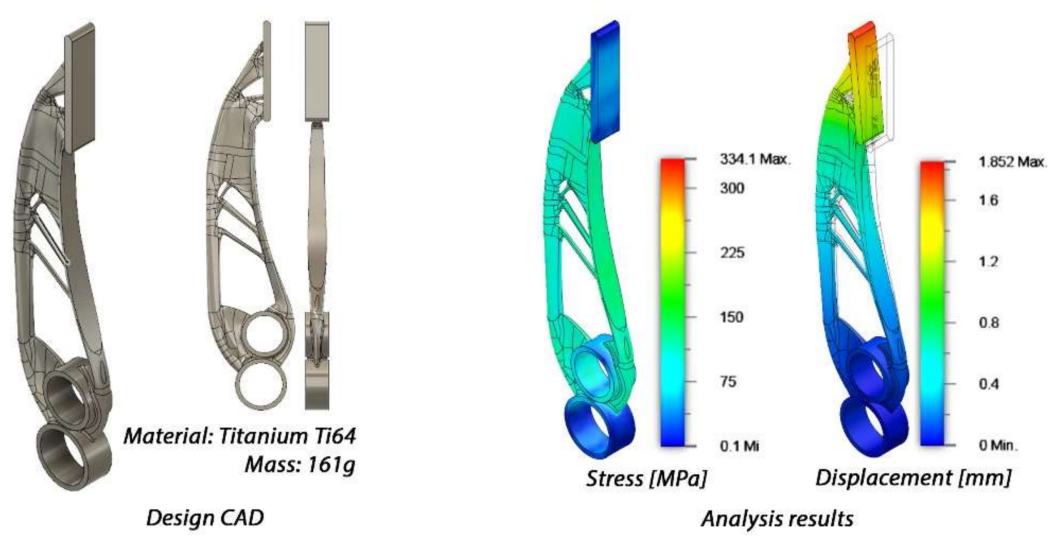

Figure 15. Titanium brake pedal designed by adopting GD tools.

\section{Results}

The following figure (Figure 16) compares the design of the traditional approach (Figure 3), adopted as the baseline, with the results of the TO (Figure 5) and GD (Figure 8) approaches for the design of an aluminum rocker. In particular, the comparison was performed with the same material and FoS achieved by the design solution obtained through the traditional approach (Figure 16a). The design solution achieved by adopting the TO tool (Figure 16b) showed a very similar mass, in fact, a very small reduction of $2.2 \%$ was observed. On the contrary, a significant improvement was observed in terms of stiffness with a $46 \%$ reduction in maximum displacement. Given the same FoS, i.e., 2.4, the GD tool generates a solution, depicted in Figure 16c, that features a significant mass reduction of $38 \%$ and reduction in maximum displacement of $42 \%$ with respect to the solution obtained through the traditional approach (Figure 16a). While, Figure 16d depicts the best solution, generated by the GD tool, in terms of FoS. This solution, in fact, is characterized by a $35 \%$ mass reduction, a $30 \%$ reduction in maximum displacement, and a $25 \%$ increase in the minimum FoS.

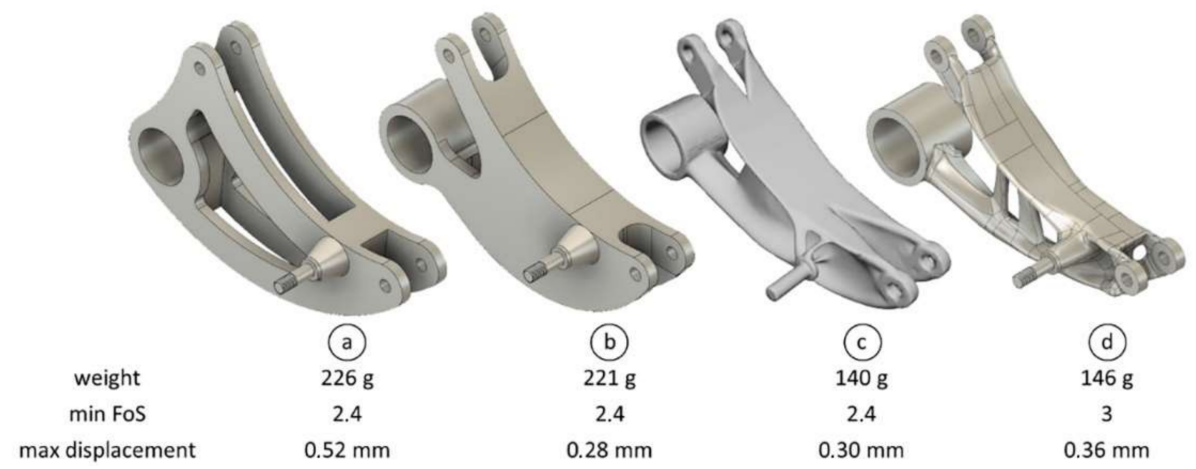

Figure 16. Aluminum rocker designed through a traditional approach (a), with TO (b) and GD $(\mathbf{c}, \mathbf{d})$ tools.

By comparing the results depicted in Figure 15, it is therefore evident that both TO and GD approaches allow to improve the design of the rocker obtained through the conventional approach.

The next figure (Figure 17) shows the results of the rocker redesigned in titanium by adopting the TO (Figure 7) and GD (Figure 9) tools. In particular, the design obtained through the GD approach (Figure 17b) allows to achieve a 33\% weight reduction with respect to the design obtained with the adoption of the TO tool (Figure 17a). 


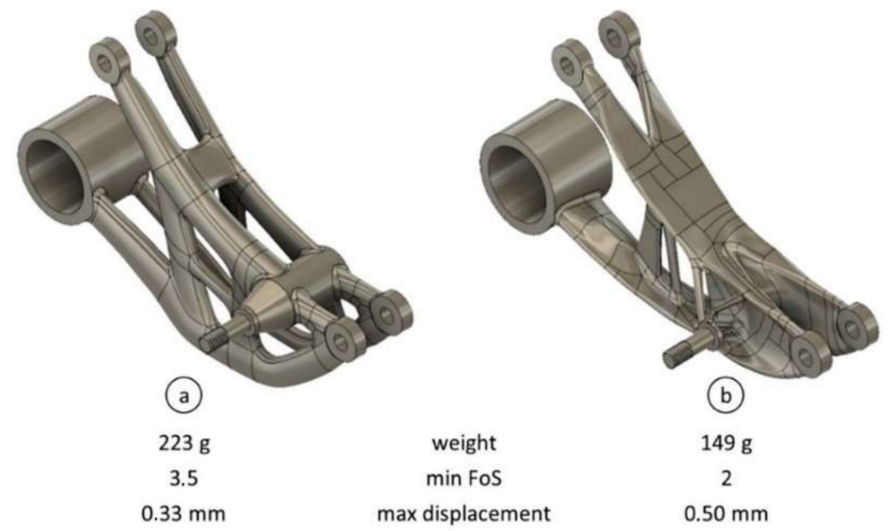

Figure 17. Titanium rocker design obtained through TO (a) and GD (b) tools.

The following figure (Figure 18) depicts the results obtained for the redesign of the brake pedal through the adoption of TO and GD tools. From the comparison with the component designed through the conventional approach (Figure 18a), it emerges that the TO approach allows to generate a solution (Figure 18b) that improves performance, specifically a $42 \%$ reduction in maximum displacement and a $9 \%$ increase in the minimum FoS. The GD approach allows to further improve the solution obtained by using the TO. In particular, the best solution is the one made of aluminum (Figure 18c) for which there is an $8.5 \%$ reduction in mass, a $58 \%$ reduction in the maximum displacement, and a $100 \%$ increase in the safety factor. Concerning the best solution in titanium (Figure 18d), realized through the GD approach, it is worse than the aluminum version (Figure 18c) but still has some improvements compared to the one obtained through the traditional approach (Figure 18a) as it features a $8.5 \%$ mass reduction, 36\% displacement reduction, and of 33\% increase of the SoF.
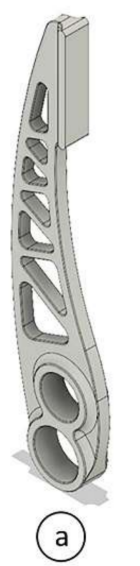

weight

$\min$ FoS

max displacement
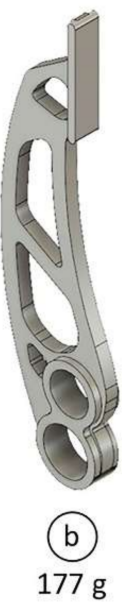

2.4
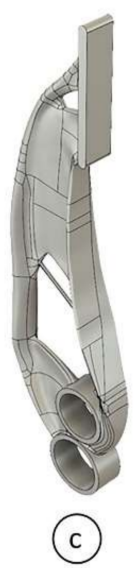

$162 \mathrm{~g}$

4.2

$1.22 \mathrm{~mm}$
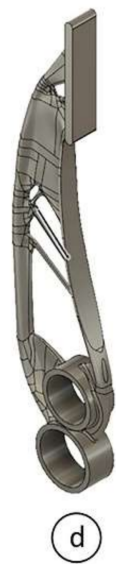

$161 \mathrm{~g}$

2.8

$1.85 \mathrm{~mm}$

Figure 18. Brake pedal designed through a traditional approach $(\mathbf{a})$, with $\mathrm{TO}(\mathbf{b})$ and $\mathrm{GD}(\mathbf{c}, \mathbf{d})$ tools.

\section{Conclusions}

The paper focused on two design approaches that can be used in industrial contexts when the goal is to produce high-performance products. In fact, the introduction of optimization tools in the product development process pushes toward simulation-driven design approaches which imply a significant change in the role of the designer. This is due to the fact that these optimization tools can be adopted in the conceptual and modeling stages of the design process in order to support engineers in defining the geometry of the 3D models. As a result, as demonstrated in the paper, if on the first side the role of the 
designer is considerably reduced compared to a traditional design approach, on the other side, these tools allow to achieve better results in terms of mechanical performance. In this context, AM technologies play a key role as they allow to take full advantage of the benefits offered by these optimization tools.

Specifically, TO tools and the more recent GD tools were considered. The paper highlighted how the design process changes based on the type of optimization tool used and what the differences are, in terms of performance, for the same case study. In particular, a rocker arm and a brake pedal for Formula Student race car were taken into consideration. The comparison of the two different approaches offers a reflection on the evolution of the traditional approach when TO and GD tools are used, and highlights the potentials and limitations of these optimization tools when adopted in an integrated manner with the CAD systems.

In particular, what emerged from this study is that both TO and GD tools can be efficiently adopted early in a design process oriented to AM in order to create a geometry driven by functional requirements or to redesign components to make them lighter and stronger in the search for greater performance. In fact, the design of the rocker, obtained through the conventional approach, was improved thanks to the adoption of the TO approach by $2.2 \%$ in mass reduction and $46 \%$ in stiffness. The use of the GD approach allowed to reach similar results in terms of stiffness, with a $42 \%$ reduction in the maximum displacement, and a significant improvement in mass reduction of $38 \%$. Additionally, in the case study of the brake pedal, the adoption of TO allows to improve performances with a $42 \%$ reduction in maximum displacement and a $9 \%$ increase in the minimum FoS. The GD approach allows to further improve these performances, with an 8,5\% reduction in mass, $58 \%$ reduction in the maximum displacement, and a $100 \%$ increase in the safety factor. Then, in both cases, the GD approach provides better results than TO. This is due to the fact that TO tools suffer the limitations due to the definition of a given design space which leads to a local optimum instead of the optimal solution. In other words, the optimum material distribution is influenced by the initial boundary conditions defined by the engineer [69]. As a consequence, different initial design spaces lead to different solutions in the TO approach. In fact, as shown in Figures 11 and 12, multiple topological analyses with different initial design space and objective functions may need to be performed to obtain an improved solution. On the contrary, the GD tools do not require an initial design space and allow designers to achieve the best-optimized solution. In addition to the results of the specific case studies, from the comparison of the two different approaches, it emerges that one of the most evident differences consists in the fact that GD tools allow to shorten and make more efficient the design process as they offer a synthetic comparative picture of the different solutions that support and simplify the designer's choice in identifying the optimal solution for the specific application case. On the contrary, regarding the TO tools, the optimization and subsequent validation of multiple concepts could be time-consuming because of the translation and redesign stages. In fact, as shown by the case studies, it is necessary to perform the redesign of the TO results by means of a CAD system in order to meet designer needs and satisfy manufacturing constraints. This implies that in the following stages it is necessary to validate the structural behavior and manufacturability of the redesigned model by implementing an iterative process. In spite of this, as also emerged from the results of the proposed case studies, the results of the TO approach could still be a suboptimal product.

Furthermore, as abovementioned in Section 2, unlike TO, GD tools offer better integration with CAD systems and this allows designers to model, optimize, and eventually refine the geometry of the component within a unique design and simulation environment without the loss of data due to the translation and redesign operations. In fact, the geometries provided by the GD tool's algorithms can be directly edited and refined by designers in the post-processing phase by means of a set of sculpting and editing features.

One other aspect that emerged from the comparison is that GD tools simultaneously investigate different materials and technological constraints with the consequence that 
designers can save time while fully exploring the options that encompass the design space. GD, in fact, provides many design solutions as a combination of different structures and materials in a single simulation, while TO provides a single design solution. Another aspect that should not be overlooked is that GD tools offer the possibility of defining an initial design space that will be optimized and this does not significantly affect the results of the algorithm. On the contrary, different initial design spaces lead to different solutions in the TO approach.

Author Contributions: Conceptualization, L.B. and M.M.; methodology, L.B. and M.M.; formal analysis, L.B. and M.M.; writing—original draft preparation, L.B. and M.M.; writing-review and editing, L.B. and M.M. All authors have read and agreed to the published version of the manuscript.

Funding: This research received no external funding.

Institutional Review Board Statement: Not applicable.

Informed Consent Statement: Not applicable.

Data Availability Statement: Not applicable.

Conflicts of Interest: The authors declare no conflict of interest.

\section{Nomenclature}

$\begin{array}{ll}\text { AM } & \text { Additive Manufacturing } \\ \text { CAD } & \text { Computer Aided Design } \\ \text { CAE } & \text { Computer Aided Engineering } \\ \text { CAM } & \text { Computer Aided Manufacturing } \\ \text { CAx } & \text { Computer Aided Technologies } \\ \text { CNC } & \text { Computer Numerical Control } \\ \text { DMLS } & \text { Direct Metal Laser Sintering } \\ \text { FEA } & \text { Finite Element Analysis } \\ \text { FEM } & \text { Finite Element Method } \\ \text { FoS } & \text { Factor of Safety } \\ \text { GD } & \text { Generative Design } \\ \text { TO } & \text { Topology Optimization }\end{array}$

\section{References}

1. Tang, Y.; Zhao, Y.F. A survey of the design methods for Additive Manufacturing to improve functional performance. Rapid Prototyp. J. 2016, 22, 569-590. [CrossRef]

2. Wiberg, A.; Persson, J.; Ölvander, J. Design for Additive Manufacturing-A review of available design methods and software. Rapid Prototyp. J. 2019, 25, 1080-1094. [CrossRef]

3. Levy, G.N.; Schindel, R.; Kruth, J. Rapid manufacturing and rapid tooling with layer manufacturing (LM) technologies, state of the art and future perspectives. CIRP Ann. 2013, 52, 589-609. [CrossRef]

4. Kruth, J.-P.; Leu, M.C.; Nakagawa, T. Progress in Additive Manufacturing and Rapid Prototyping. CIRP Ann. Manuf. Technol. 1998, 47, 525-540. [CrossRef]

5. Vandenbroucke, B.; Kruth, J.-P. Selective laser melting of biocompatible metals for rapid manufacturing of medical parts. Rapid Prototyp. J. 2007, 13, 196-203. [CrossRef]

6. Leal, R.; Barreiros, F.; Alves, M.; Romeiro, F.; Vasco, J.C.; Santos, M.; Marto, C. Additive Manufacturing tooling for the automotive industry. Int. J. Adv. Manuf. Technol. 2017, 92, 1671-1676. [CrossRef]

7. Ituarte, I.F.; Chekurov, S.; Tuomi, J.; Mascolo, J.E.; Zanella, A.; Springer, P.; Partanen, J. Digital manufacturing applicability of a laser sintered component for automotive industry: A case study. Rapid Prototyp. J. 2018, 24, 1203-1211. [CrossRef]

8. Ngo, T.D.; Kashani, A.; Imbalzano, G.; Nguyen, K.T.Q.; Hui, D. Additive Manufacturing (3D printing): A review of materials, methods, applications and challenges. Compos. Part B Eng. 2018, 143, 172-196. [CrossRef]

9. Elsayed, M.; Ghazy, M.; Youssef, Y.; Essa, K. Optimization of SLM process parameters for Ti6Al4V medical implants. Rapid Prototyp. J. 2019, 25, 433-447. [CrossRef]

10. Dankwort, C.W.; Weidlich, R.; Guenther, B.; Blaurock, J.E. Engineers' CAx education-It's not only CAD. Comput. Aided Des. 2004, 36, 1439-1450. [CrossRef]

11. Barbieri, L.; Calzone, F.; Muzzupappa, M. Form and function: Functional optimization and Additive Manufacturing. In Advances on Mechanics, Design Engineering and Manufacturing II; Springer: Cham, Switzerland, 2019; pp. 649-658. [CrossRef] 
12. Bathe, K.J. Finite Element Procedures; Prentice Hall: Upper Saddle River, NJ, USA, 1996.

13. Sandberg, M. Design for Manufacturing: Methods and Applications Using Knowledge Engineering. Ph.D. Dissertation, Luleå Tekniska Universitet, Luleå, Sweden, 2007.

14. Thompson, M.K.; Moroni, G.; Vaneker, T.; Fadel, G.; Campbell, R.I.; Gibson, I.; Bernard, A.; Schulz, J.; Graf, P.; Ahuja, B.; et al. Design for Additive Manufacturing: Trends, opportunities, considerations, and constraints. CIRP Ann. 2016, 65, 737-760. [CrossRef]

15. Pagac, M.; Hajnys, J.; Halama, R.; Aldabash, T.; Mesicek, J.; Jancar, L.; Jansa, J. Prediction of Model Distortion by FEM in 3D Printing via the Selective Laser Melting of Stainless Steel AISI 316L. Appl. Sci. 2021, 11, 1656. [CrossRef]

16. Afazov, S.; Denmark, W.A.D.; Lazaro Toralles, B.; Holloway, A.; Yaghi, A. Distortion prediction and compensation in selectivelaser melting. Addit. Manuf. 2017, 17, 15-22. [CrossRef]

17. Sotomayor, N.S.; Caiazzo, F.; Alfieri, V. Enhancing Design for Additive Manufacturing Workflow: Optimization, Design and Simulation Tools. Appl. Sci. 2021, 11, 6628. [CrossRef]

18. Bendsoe, M.P.; Sigmund, O. Topology Optimization: Theory, Methods, and Applications; Springer: Berlin/Heidelberg, Germany, 2003.

19. Bendsøe, M.P. Optimization of Structural Topology, Shape, and Material; Springer: Berlin/Heidelberg, Germany, 1995.

20. Sigmund, O.; Maute, K. Topology Optimization Approaches: A comparative review. Struct. Multidiscip. Optim. 2013, 48, 1031-1055. [CrossRef]

21. Ribeiro, T.; Bernardo, L.; Andrade, J. Topology Optimisation in Structural Steel Design for Additive Manufacturing. Appl. Sci. 2021, 11, 2112. [CrossRef]

22. Vlah, D.; Žavbi, R.; Vukašinović, N. Evaluation of topology optimization and generative design tools as support for conceptual design. In Proceedings of the Design Society: Design Conference, Cavtat, Croatia, 26-29 October 2020; Cambridge University Press: Cambridge, UK, 2020; Volume 1, pp. 451-460. [CrossRef]

23. Zhu, J.; Zhang, W.-H.; Xia, L. Topology Optimization in Aircraft and Aerospace Structures Design. Arch. Comput. Methods Eng. 2016, 23, 595-622. [CrossRef]

24. Dunning, P.; Stanford, B.K.; Kim, H.A. Coupled aerostructural topology optimization using a level set method for 3D aircraft wings. Struct. Multidiscip. Optim. 2015, 51, 1113-1132. [CrossRef]

25. Li, C.; Kim, I.Y.; Jeswiet, J. Conceptual and detailed design of an automotive engine cradle by using topology, shape, and size optimization. Struct. Multidiscip. Optim. 2014, 51, 547-564. [CrossRef]

26. Chuang, C.-H.; Chen, S.; Yang, R.-J.; Vogiatzis, P. Topology optimization with Additive Manufacturing consideration for vehicle load path development. Int. J. Numer. Methods Eng. 2018, 113, 1434-1445. [CrossRef]

27. Sutradhar, A.; Park, J.; Carrau, D.; Nguyen, T.; Miller, M.J.; Paulino, G.H. Designing patient-specific 3D printed craniofacial implants using a novel topology optimization method. Med. Biol. Eng. Comput. 2016, 54, 1123-1135. [CrossRef] [PubMed]

28. Wang, X.; Xu, S.; Zhou, S.; Xu, W.; Leary, M.; Choong, P.; Qian, M.; Brandt, M.; Xie, Y.M. Topological design and Additive Manufacturing of porous metals for bone scaffolds and orthopaedic implants: A review. Biomaterials 2016, 83, 127-141. [CrossRef] [PubMed]

29. Ma, H.; Wang, J.; Lu, Y.; Guo, Y. Lightweight design of turnover frame of bridge detection vehicle using topology and thickness optimization. Struct. Multidiscip. Optim. 2019, 59, 1007-1019. [CrossRef]

30. Wu, S.; Zhang, Y.; Liu, S. Topology optimization for minimizing the maximum temperature of transient heat conduction structure. Struct. Multidiscip. Optim. 2019, 60, 69-82. [CrossRef]

31. Eschenauer, H.A.; Niels, O. Topology optimization of continuum structures: A review. Appl. Mech. Rev. 2001, 54, 331-390. [CrossRef]

32. Harzheim, L.; Gerhard, G. A review of optimization of cast parts using topology optimization. Struct. Multidiscip. Optim. 2006, 31, 388-399. [CrossRef]

33. Dbouk, T. A review about the engineering design of optimal heat transfer systems using topology optimization. Appl. Therm. Eng. 2017, 112, 841-854. [CrossRef]

34. Cucinotta, F.; Guglielmino, E.; Longo, G.; Risitano, G.; Santonocito, D.; Sfravara, F. Topology Optimization Additive Manufacturing-Oriented for a Biomedical Application. In Advances on Mechanics, Design Engineering and Manufacturing II; Springer: Cham, Switzerland, 2019; pp. 184-193.

35. Hällgren, S.; Pejryd, L.; Ekengren, J. (Re)Design for Additive Manufacturing. Procedia CIRP 2016, 50, 246-251. [CrossRef]

36. Mohiuddin, M.V.; Khan, M.A. Re-design of an Aircraft Bracket Using Topology Optimization Technique. Int. J. Mech. Eng. 2020, 7, 42-53. [CrossRef]

37. Dalpadulo, E.; Gherardini, F.; Pini, F.; Leali, F. Integration of Topology Optimisation and Design Variants Selection for Additive Manufacturing-Based Systematic Product Redesign. Appl. Sci. 2020, 10, 7841. [CrossRef]

38. Nieto, D.; Sánchez, D. Design for Additive Manufacturing: Tool Review and a Case Study. Appl. Sci. 2021, 11, 1571. [CrossRef]

39. Raffaeli, R.; Lettori, J.; Schmidt, J.; Peruzzini, M.; Pellicciari, M. A Systematic Approach for Evaluating the Adoption of Additive Manufacturing in the Product Design Process. Appl. Sci. 2021, 11, 1210. [CrossRef]

40. Lindemann, C.; Reiher, T.; Jahnke, U.; Koch, R. Towards a sustainable and economic selection of part candidates for Additive Manufacturing. Rapid Prototyp. J. 2015, 21, 216-227. [CrossRef] 
41. Barbieri, L.; Bruno, F.; Muzzupappa, M.; Cugini, U. Design automation tools as a support for knowledge management in topology optimization. In Proceedings of the ASME 2008 International Design Engineering Technical Conferences and Computers and Information in Engineering Conference, American Society of Mechanical Engineers Digital Collection, Brooklyn, NY, USA, 3-6 August 2008; pp. 1227-1234. [CrossRef]

42. Larsen, S.; Jensen, C.G. Converting Topology Optimization Results into Parametric CAD Models. Comput. Aided Des. Appl. 2009, 6, 407-418. [CrossRef]

43. Muzzupappa, M.; Barbieri, L.; Bruno, F. Integration of topology optimisation tools and knowledge management into the virtual Product Development Process of automotive components. Int. J. Prod. Dev. 2011, 14, 14. [CrossRef]

44. Muzzupappa, M.; Barbieri, L.; Bruno, F.; Cugini, U. Methodology and Tools to Support Knowledge Management in Topology Optimization. J. Comput. Inf. Sci. Eng. 2010, 10, 044503. [CrossRef]

45. Stangl, T.; Wartzack, S. Feature based interpretation and reconstruction of structural topology optimization results. In Proceedings of the DS 80-6 Proceedings of the 20th International Conference on Engineering Design (ICED 15) Vol 6: Design Methods and Tools-Part 2, Milan, Italy, 27-30 July 2015; pp. 235-244.

46. Zegard, T.; Paulino, G.H. Bridging topology optimization and Additive Manufacturing. Struct. Multidiscip. Optim. 2016, 53, 175-192. [CrossRef]

47. Jiu, L.; Zhang, W.; Meng, L.; Zhou, Y.; Chen, L. A CAD-oriented structural topology optimization method. Comput. Struct. 2020, 239, 106324. [CrossRef]

48. Rosso, S.; Uriati, F.; Grigolato, L.; Meneghello, R.; Concheri, G.; Savio, G. An Optimization Workflow in Design for Additive Manufacturing. Appl. Sci. 2021, 11, 2572. [CrossRef]

49. Bendsøe, M.P. Optimal shape design as a material distribution problem. Struct. Optim. 1989, 1, 193-202. [CrossRef]

50. Sigmund, O. On the usefulness of non-gradient approaches in topology optimization. Struct. Multidiscip. Optim. 2011, 43, 589-596. [CrossRef]

51. Kaminakis, N.T.; Stavroulakis, G. Topology optimization for compliant mechanisms, using evolutionary-hybrid algorithms and application to the design of auxetic materials. Compos. Part B Eng. 2012, 43, 2655-2668. [CrossRef]

52. Bendsøe, M.P.; Sigmund, O. Material interpolation schemes in topology optimization. Arch. Appl. Mech. 1999, 69, 635-654. [CrossRef]

53. Caetano, I.; Santos, L.; Leitão, A. Computational design in architecture: Defining parametric, generative, and algorithmic design. Front. Arch. Res. 2020, 9, 287-300. [CrossRef]

54. McKnight, M. Generative Design: What it is? How is it being used? Why it's a game changer. KnE Eng. 2017, 2, 176-181. [CrossRef]

55. McCormack, J.P.; Dorin, A.; Innocent, T.C. Generative design: A paradigm for design research. In Future Ground; Redmond, J., Durling, D., de Bono, A., Eds.; Monash University: Melbourne, Australia, 2005; Volume 2.

56. Sun, H.; Ma, L. Generative Design by Using Exploration Approaches of Reinforcement Learning in Density-Based Structural Topology Optimization. Designs 2020, 4, 10. [CrossRef]

57. Frazer, J.H. An Evolutionary Architecture; Architectural Association Publications: London, UK, 1995.

58. Caldas, L. Generation of energy-efficient architecture solutions applying GENE_ARCH: An evolution-based generative design system. Adv. Eng. Inform. 2008, 22, 59-70. [CrossRef]

59. Abdelmohsen, S. Reconfiguring Architectural Space Using Generative Design and Digital Fabrication: A Project Based Course. In Proceedings of the XVII Conference of the Iberoamerican Society of DigitalGraphics_SIGraDi: Knowledge-Based Design; Editora Edgard Blucher, Ltd.: São Paulo, Brazil, 2013; pp. 391-395.

60. Chaszar, A.; Joyce, S.C. Generating freedom: Questions of flexibility in digital design and architectural computation. Int. J. Arch. Comput. 2016, 14, 167-181. [CrossRef]

61. Mountstephens, J.; Teo, J. Progress and Challenges in Generative Product Design: A Review of Systems. Computers 2020, 9, 80. [CrossRef]

62. Wu, J.; Qian, X.; Wang, M.Y. Advances in generative design. Comput. Aided Des. 2019, 116, 102733. [CrossRef]

63. Buonamici, F.; Carfagni, M.; Furferi, R.; Volpe, Y.; Governi, L. Generative Design: An Explorative Study. Comput. Aided Des. Appl. 2020, 18, 144-155. [CrossRef]

64. Bhat, A.; Gupta, V.; Aulakh, S.S.; Elsen, R.S. Generative design and analysis of a double-wishbone suspension assembly: A methodology for developing constraint oriented solutions for optimum material distribution. J. Eng. Des. Technol. 2021. [CrossRef]

65. Schelhorn, L.; Gosch, M.; Debeugny, L.; Schröter, P.; Schwarz, W.; Soller, S. Optimal Design and Process Simulation for Additive Manufacturing. In Proceedings of the 8th European Conference for Aeronautics and Space Sciences, Madrid, Spain, 1-4 July 2019.

66. Marinov, M.; Amagliani, M.; Barback, T.; Flower, J.; Barley, S.; Furuta, S.; Charrot, P.; Henley, I.; Santhanam, N.; Finnigan, G.T.; et al Generative Design Conversion to Editable and Watertight Boundary Representation. CAD Comput. Aided Des. 2019, 115, 194-205. [CrossRef]

67. Autodesk Fusion 360. Available online: https:/ /www.autodesk.com/products/fusion-360 (accessed on 11 February 2022).

68. Khaing, M.; Fuh, J.; Lu, L. Direct metal laser sintering for rapid tooling: Processing and characterisation of EOS parts. J. Mater. Process. Technol. 2001, 113, 269-272. [CrossRef]

69. Tyflopoulos, E.; Tollnes, F.D.; Steinert, M.; Olsen, A. State of the art of generative design and topology optimization and potential research needs. In Proceedings of the DS 91: Proceedings of NordDesign 2018, Linköping, Sweden, $14-17$ August 2018. 